\title{
The effect of residual stresses in the lateral- torsional buckling of steel I-beams at elevated temperature
}

\author{
P.M.M. Vila Real ${ }^{\mathrm{a}, *}$, R. Cazeli ${ }^{\mathrm{b}}$, L. Simões da Silva ${ }^{\mathrm{c}}$, \\ A. Santiago ${ }^{c}$, P. Piloto ${ }^{\mathrm{d}}$ \\ a Department of Civil Engineering, University of Aveiro, 3810 Aveiro, Portugal \\ b University of Aveiro, 3810-193 Aveiro, Portugal \\ c University of Coimbra, 3030-290 Coimbra, Portugal \\ d Polytechnic Institute of Bragança, 5300 Bragança, Portugal
}

\begin{abstract}
When a beam is bent about its major axis, it may twist and move laterally, before it reaches its elastic/plastic resistance in bending. Although the problem of lateral-torsional buckling of steel beams at room temperature has a well-established solution, the same problem at elevated temperature has not. A numerical investigation of the lateral-torsional buckling of steel I-beams subjected to a temperature variation from room temperature up to 700 ${ }^{\circ} \mathrm{C}$, with the aim of assessing the effects of the residual stresses in this mechanism of failure, is presented in this paper.

To this purpose, a geometrically and materially non-linear finite element program has been used to determine the lateral-torsional resistance of steel I-beams at elevated temperatures, using the material properties of Eurocode 3, Part 1-2. The numerical results have been compared to the results of the simple model presented in Eurocode 3, Part 1-2 (1995) and a new proposal that is being considered for approval.
\end{abstract}

(C) 2003 Elsevier Ltd. All rights reserved.

Keywords: Residual stresses; Lateral-torsional buckling; Temperature; Fire

\footnotetext{
${ }^{*}$ Corresponding author. Tel.: +351-234-370049; fax: +351-234-370094.

E-mail address: pvreal@civil.ua.pt (P.M.M. Vila Real).
} 


\section{Nomenclature}

$f_{\mathrm{y}} \quad$ yield strength

$k_{\mathrm{y}, \theta, \text { com }}$ reduction factor for the yield strength at the maximum temperature in the compression flange $\theta_{a, \text { com }}$, reached at time $t$

$k_{\mathrm{E}, \theta, \text { com }}$ reduction factor for the slope of the linear elastic range at the maximum steel temperature in the compression flange $\theta_{a, \text { com }}$ reached at time $t$

$l \quad$ length of the beams

$M_{\mathrm{b}, \mathrm{fi}, t, \mathrm{Rd}}$ buckling resistance moment in the fire design situation

$M_{\mathrm{E}} \quad$ elastic critical moment for lateral-torsional buckling

$M_{\mathrm{fi}, \theta, \mathrm{Rd}}$ design moment resistance of a Class 1 or 2 cross-section with a uniform temperature $\theta_{a}$

$M_{\mathrm{Rd}}, M_{\mathrm{P}}$ plastic moment resistance of the gross cross-section, $M_{\mathrm{pl}, \mathrm{Rd}}$ for normal temperature

$M_{\mathrm{SAFIR}}$ buckling resistance moment in the fire design situation given by SAFIR

$t \quad$ time

$w_{\mathrm{pl}, \mathrm{y}} \quad$ plastic section modulus

\section{Greek letters}

$\alpha \quad$ imperfection factor

$\gamma_{M 0} \quad$ partial safety factor (usually $\gamma_{M 0}=1.0$ )

$\gamma_{M, \mathrm{fi}} \quad$ partial safety factor for the fire situation (usually $\gamma_{M, \mathrm{fi}}=1.0$ )

$\lambda_{\text {LT }} \quad$ slenderness

$\bar{\lambda}_{\mathrm{LT}} \quad$ non-dimensional slenderness at room temperature

$\bar{\lambda}_{\mathrm{LT}, \theta, \mathrm{com}}$ non-dimensional slenderness for the maximum temperature in the compression flange $\theta_{a, \text { com }}$

$\bar{\lambda}_{\mathrm{LT}, \mathrm{fi}} \quad$ non-dimensional slenderness in the fire design situation

$\chi_{\mathrm{LT}, \mathrm{fi}}$ reduction factor for lateral-torsional buckling in the fire design situation

\section{Introduction}

Slender beams, subjected to bending loads in the plane of their greatest flexural rigidity, can buckle by combined twist and lateral bending, called lateral-torsional buckling instability. Due to the low torsional and lateral flexural stiffness of slender beams, their cross-section may rotate and deflect laterally, as in torsional-flexural instability of columns caused by axial compression. Although the solution to the problem of lateral-torsional buckling of steel beams at room temperature is well known [1], there is no solution for this problem at elevated temperature. Among 
the more important factors which affect the lateral stability of beams in actual structures are [2]:

- initial bow;

- initial twist in the section;

- accidental eccentricities of loading;

- premature yielding due to the presence of residual stresses.

In this paper, the influence of the residual stresses in the lateral-torsional buckling of unrestrained steel I-beams has been numerically investigated. The results were compared to the simple model presented in Eurocode 3, Part 1-2 [3] and to a new proposal [4-6] that is being considered for approval in the Eurocode. This proposal was based on the numerical results from the SAFIR program, a geometrical and materially non-linear code specially developed for the analysis of structures submitted to fire [7]. In the numerical analyses, a three-dimensional (3D) beam element has been used. It is based on the following formulations and hypotheses:

- Displacement type element in a total co-rotational description.

- Prismatic element.

- The displacement of the node line is described by the displacements of the three nodes of the element, two nodes at each end supporting seven degrees of freedom, three translations, three rotations and the warping amplitude, plus one node at the mid-length supporting one degree of freedom, the non-linear part of the longitudinal displacement.

- The Bernoulli hypothesis is considered, i.e., plane sections remain plane and perpendicular to the longitudinal axis and no shear energy is considered.

- No local buckling is taken into account, which is the reason why only Class 1 and Class 2 sections can be used [8].

- The strains are small (von Kármán hypothesis), i.e.

$$
\frac{1}{2} \frac{\partial u}{\partial x} \ll 1
$$

where $u$ is the longitudinal displacement and $x$ is the longitudinal co-ordinate.

- The angles between the deformed longitudinal axis and the undeformed but translated longitudinal axis are small, i.e.,

$$
\sin \varphi \cong \varphi \text { and } \cos \varphi \cong 1
$$

where $\varphi$ is the angle between the arc and the cord of the beam finite element.

- The longitudinal integrations are numerically calculated using Gauss' method.

- The cross-section is discretised by means of triangular or quadrilateral fibres. At every longitudinal point of integration, all variables, such as temperature, strain, stress, etc., are uniform in each fibre.

- The tangent stiffness matrix is evaluated at each iteration of the convergence process (pure Newton-Raphson method). 


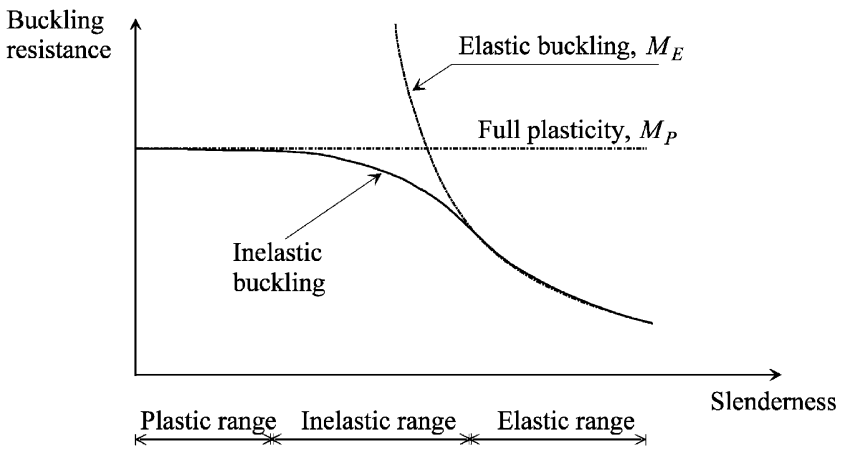

Fig. 1. Effect of slenderness on the buckling resistance.

- Residual stresses are considered by means of initial and constant strains [9].

- The material behaviour in case of strain unloading is elastic, with the elastic modulus equal to Young's modulus at the origin of the stress-strain curve. In the same cross-section, some fibres that have yielded may therefore exhibit a decreased tangent modulus because they are still on the loading branch, whereas, at the same time, some other fibres behave elastically. The plastic strain is presumed not to be affected by a change in temperature [10].

Numerical simulations have demonstrated clearly that beams with closely spaced restraints can reach the plastic moment $M_{\mathrm{P}}$, while long unrestrained spans effectively fail by elastic lateral-torsional instability at moments that are very close to the theoretical elastic critical moment $M_{\mathrm{E}}$ (see Fig. 1).

A slender beam which has low resistance to lateral bending and torsion may buckle in the elastic range by deflecting and twisting out of the plane of loading. This is the so-called elastic flexural-torsional buckling phenomena. The resistance of a beam to elastic buckling increases as its slenderness decreases, and a steel beam of moderate stiffness may yield before its elastic buckling load is reached. Yielding is caused by a combination of the stresses induced by the applied loads with any residual stresses which remain after the manufacturing process is completed. Yielding reduces the effective out-of-plane rigidities, and decreases the buckling resistance below the elastic value as shown in Fig. 1.

The influence of the residual stresses is higher for intermediate slenderness of the beams as it will be shown in this paper.

\section{Case study}

Simply supported steel I-beams of the European series IPE 220 with fork supports (the beams cannot deflect laterally or twist at the supports) submitted to uniform moment as shown in Fig. 2 were studied. A longitudinal geometric 


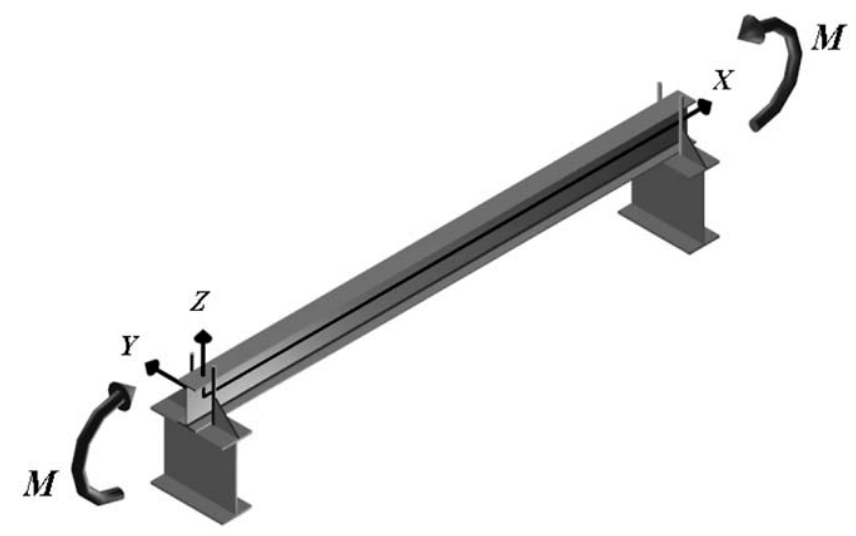

Fig. 2. Simply supported beam submitted to moments at the ends.

imperfection of sinusoidal type as been assumed

$$
y(x)=\frac{l}{1000} \sin \left(\frac{\pi x}{l}\right)
$$

where $l$ is the beam length.

The residual stresses adopted are constant across the thickness of the web and of the flanges. Triangular distribution as in Fig. 3, with a maximum value of $0.3 \times$ $235 \mathrm{MPa}$, for the $\mathrm{S} 235$ steel as well as for the S355 steel has been adopted [11].

In the numerical calculations, this residual stress distribution was approximated by the self-equilibrated diagram of Fig. 4.

Fig. 5 shows the adopted stress-strain relationship at elevated temperatures for grade S 235 steel.

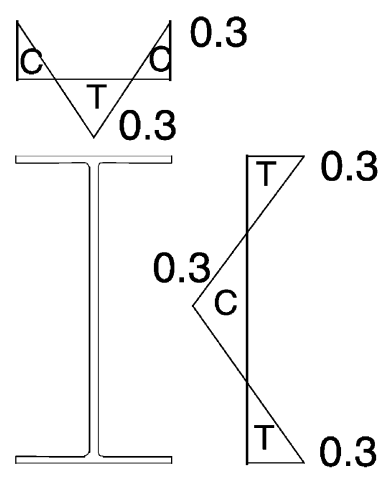

Fig. 3. Residual stresses: $\mathrm{C}$-compression; $\mathrm{T}$-tension. 


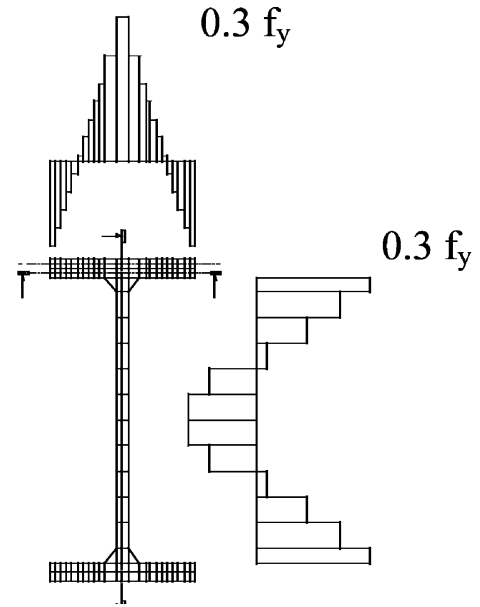

Fig. 4. Shape of the residual stresses adopted in the numerical calculations $\left(f_{\mathrm{y}}=235 \mathrm{MPa}\right)$.

\section{Analysis according to Eurocode 3}

According to Part 1.2 of Eurocode 3, the buckling resistance moment $M_{\mathrm{b}, \mathrm{fi}, t, \mathrm{Rd}}$ at time $t$ is given by

$$
M_{\mathrm{b}, \mathrm{fi}, t, \mathrm{Rd}}=\frac{\chi_{\mathrm{LT}, \mathrm{fi}}}{1.2} W_{\mathrm{pl}, \mathrm{y}} k_{\mathrm{y}, \theta, \mathrm{com}} f_{\mathrm{y}} \frac{1}{\gamma_{M, \mathrm{fi}}}
$$

where $\chi_{\mathrm{LT}, \mathrm{fi}}$ is the reduction factor for lateral-torsional buckling in the fire design situation; $W_{\mathrm{pl}, \mathrm{y}}$ is the plastic section modulus; $k_{\mathrm{y}, \theta, \mathrm{com}}$ is the reduction factor for the yield strength at the maximum temperature in the compression flange $\theta_{a, \mathrm{com}}$, reached at time $t ; \gamma_{M, \mathrm{fi}}$ is the partial safety factor for the fire situation (usually $\left.\gamma_{M, \mathrm{fi}}=1\right)$.

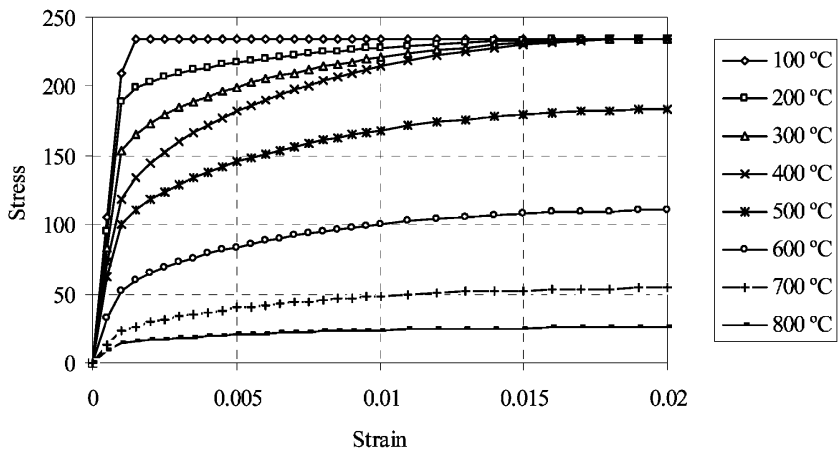

Fig. 5. Stress-strain relationship at elevated temperatures for grade S 235 steel. 
This equation is used if the non-dimensional slenderness $\bar{\lambda}_{\mathrm{LT}, \theta \text {,com }}$ for the temperature reached at time $t$ exceeds the value of 0.4. The constant 1.2 is an empirically determined value and is used as a correction factor which allows for a number of effects. The reduction factor for lateral-torsional buckling in fire design situation, $\chi_{\mathrm{LT}, \mathrm{fi}}$, is determined as for room temperature, using instead the nondimensional slenderness $\bar{\lambda}_{\mathrm{LT}, \theta, \text { com }}$ given by

$$
\bar{\lambda}_{\mathrm{LT}, \theta, \text { com }}=\bar{\lambda}_{\mathrm{LT}} \sqrt{\frac{k_{\mathrm{y}, \theta, \text { com }}}{k_{\mathrm{E}, \theta, \text { com }}}}
$$

where $\bar{\lambda}_{\mathrm{LT}}$ is the non-dimensional slenderness at room temperature; $k_{\mathrm{E}, \theta \text {,com }}$ is the reduction factor for the slope of the linear elastic range at the maximum steel temperature reached at time $t$.

The solid line of Fig. 6 shows the design curve for lateral-torsional buckling in case of fire according to Eurocode 3. For all temperatures greater than $20{ }^{\circ} \mathrm{C}$, this curve is unique and denoted EC3,fi. On the vertical axis is the ratio

$$
\frac{M_{\mathrm{b}, \mathrm{fi}, t, \mathrm{Rd}}}{M_{\mathrm{fi}, \theta, \mathrm{Rd}}}
$$

where $M_{\mathrm{b}, \mathrm{fi}, t, \mathrm{Rd}}$ is the design lateral-torsional buckling resistance moment at time $t$ of a laterally unrestrained beam, given by Eq. (2), and $M_{\mathrm{fi}, \theta, \mathrm{Rd}}$ is the design moment resistance of a Class 1 or 2 cross-section with a uniform temperature $\theta_{a}$. It may be determined from

$$
M_{\mathrm{fi}, \theta, \mathrm{Rd}}=k_{\mathrm{y}, \theta} \frac{\gamma_{M 0}}{\gamma_{M, \mathrm{fi}}} M_{\mathrm{Rd}}
$$

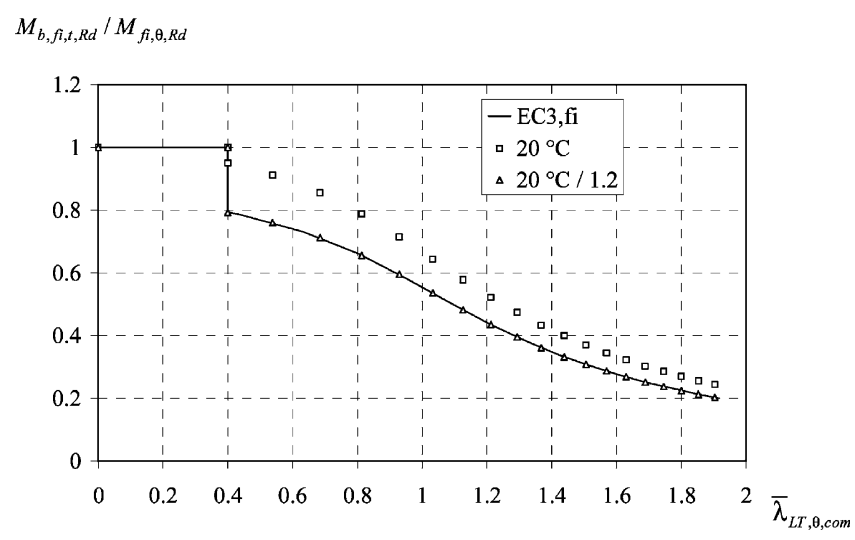

Fig. 6. Beam design curve of Eurocode 3 for fire situation $\left(\mathrm{EC} 3\right.$,fi) and at room temperature $\left(20^{\circ} \mathrm{C}\right)$. 
where $\gamma_{M 0}=1.0 ; \gamma_{M, \mathrm{fi}}=1.0$ and $M_{\mathrm{Rd}}$ is the plastic resistance of the gross cross-section $M_{\mathrm{pl}, \mathrm{Rd}}$ for normal temperature, given by

$$
M_{\mathrm{Rd}}=\frac{W_{\mathrm{pl}, \mathrm{y}} f_{\mathrm{y}}}{\gamma_{M 0}}
$$

This figure also shows that the lateral buckling design curve at elevated temperature is different from the curve at $20{ }^{\circ} \mathrm{C}$ by the empirical factor 1.2 (the curve at elevated temperature, EC3,fi, is the curve at $20{ }^{\circ} \mathrm{C}$ divided by 1.2 ). Therefore it must be emphasized that throughout this paper the ratio $M_{\mathrm{b}, \mathrm{fi}, t, \mathrm{Rd}} / M_{\mathrm{fi}, \theta, \mathrm{Rd}}$ will be used for the purposes of comparison. It is obtained as the reduction factor for lateraltorsional buckling in the fire design situation $\chi_{\mathrm{LT}, \mathrm{fi}}$ divided by 1.2, for the Eurocode 3, Part 1-2 results, i.e.

$$
\frac{M_{\mathrm{b}, \mathrm{fi}, t, \mathrm{Rd}}}{M_{\mathrm{fi}, \theta, \mathrm{Rd}}}=\frac{\chi_{\mathrm{LT}, \mathrm{fi}}}{1.2} \quad \text { for Eurocode 3, Part 1-2 results }
$$

or directly from

$$
\frac{M_{\mathrm{SAFIR}}}{M_{\mathrm{fi}, \theta, \mathrm{Rd}}} \text { for the SAFIR results }
$$

\section{Analysis according to the new proposal}

A new proposal for the lateral-torsional buckling resistance, based on numerical calculations, was proposed by Vila Real and Franssen [4,5]. According to this new proposal, that adopted the same philosophy already proposed by Franssen et al. [12] in the context of axially loaded columns subjected to fire conditions, the design buckling resistance moment of a laterally unrestrained beam with a Class 1 or 2 cross-section type is obtained as follows [4-6]:

$$
M_{\mathrm{b}, \mathrm{fi}, t, \mathrm{Rd}}=\chi_{\mathrm{LT}, \mathrm{fi}} W_{\mathrm{pl}, \mathrm{y}} k_{\mathrm{y}, \theta, \mathrm{com}} f_{\mathrm{y}} \frac{1}{\gamma_{M, \mathrm{fi}}}
$$

where $\chi_{\mathrm{LT}, \mathrm{fi}}$ is given by

$$
\chi_{\mathrm{LT}, \mathrm{fi}}=\frac{1}{\phi_{\mathrm{LT}, \theta, \mathrm{com}}+\sqrt{\left[\phi_{\mathrm{LT}, \theta, \mathrm{com}}\right]^{2}-\left[\lambda_{\mathrm{LT}, \theta, \mathrm{com}}\right]^{2}}}
$$

with

$$
\phi_{\mathrm{LT}, \theta, \mathrm{com}}=\frac{1}{2}\left[1+\alpha \bar{\lambda}_{\mathrm{LT}, \theta, \mathrm{com}}+\left(\bar{\lambda}_{\mathrm{LT}, \theta, \mathrm{com}}\right)^{2}\right]
$$

The imperfection factor $\alpha$, in this proposal, is a function of the steel grade and is given by

$$
\alpha=0.65 \sqrt{235 / f_{\mathrm{y}}}
$$




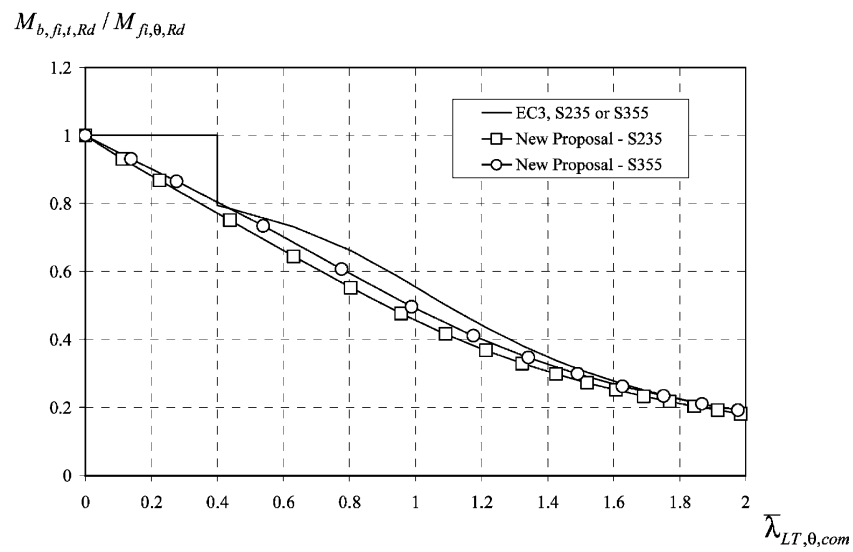

Fig. 7. Comparison between design buckling curve from EC3 and the new proposal.

where $f_{\mathrm{y}}$ represents the nominal yield strength of the material in MPa. The remaining factor $\bar{\lambda}_{\mathrm{LT}, \theta \text {.com }}$ should be calculated as in Eq. (3).

Comparing this new proposal with the Eurocode 3 formulas (see Fig. 7), it can be verified that the shape of the buckling curve is different, with the new one starting from $\chi_{\mathrm{LT}, \mathrm{fi}}=1.0$ for $\bar{\lambda}_{\mathrm{LT}, \theta, \mathrm{com}}=0.0$ but decreasing even for very low slenderness, instead of having a horizontal plateau up to $\bar{\lambda}_{\mathrm{LT}, \theta, \mathrm{com}}=0.4$ as in the Eurocode 3 [7]. The lateral-torsional buckling curve now depends on the steel grade due to the imperfection factor $\alpha$ as it can be seen in Fig. 7.

\section{Numerical results}

The numerical results for the beams at room temperature $\left(20^{\circ} \mathrm{C}\right)$ are plotted in Fig. 8. It can be seen that the results are in good agreement with the beam design curve of Eurocode 3 whenever the residual stresses are considered. It is also evident

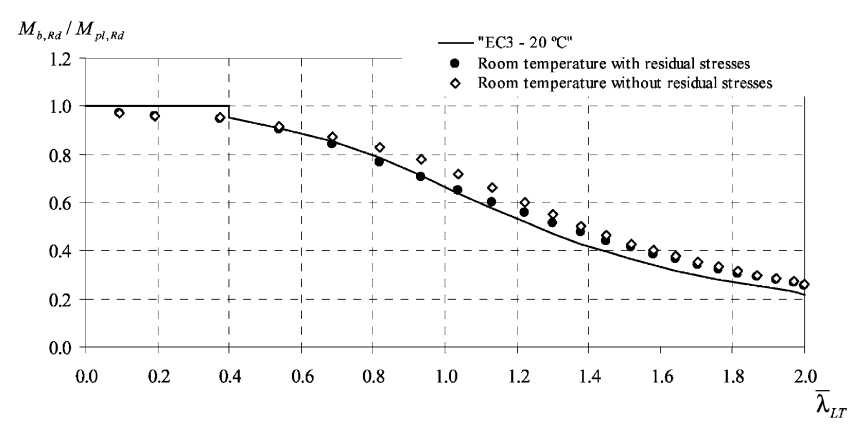

Fig. 8. Beam design curve at room temperature. 
(a)

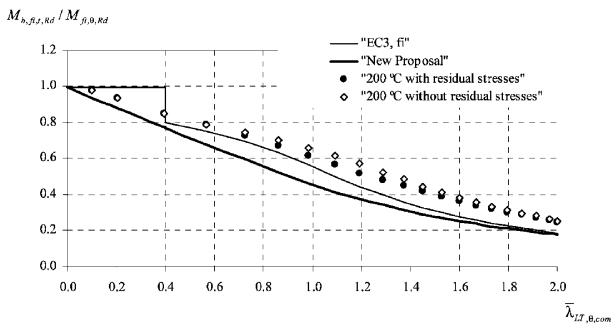

(b)

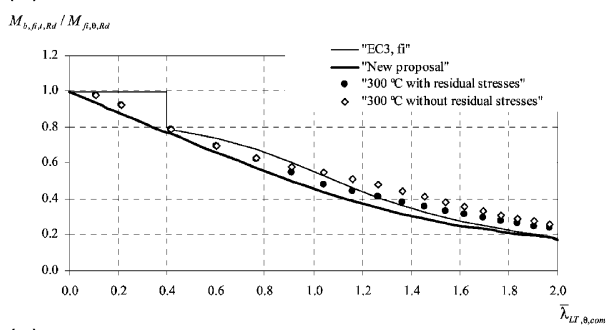

(c)

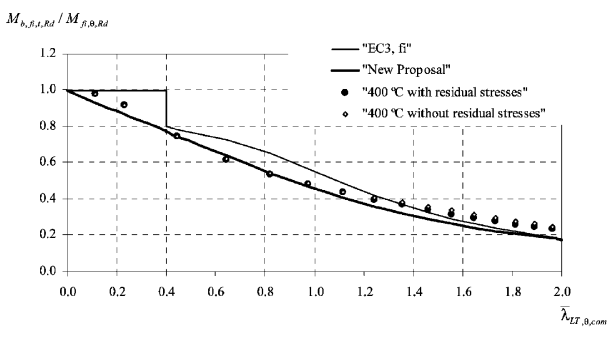

(d)

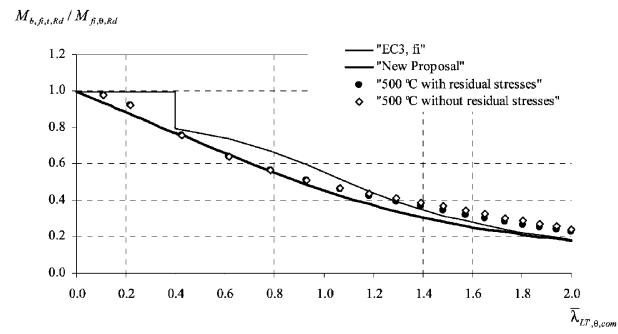

(e)

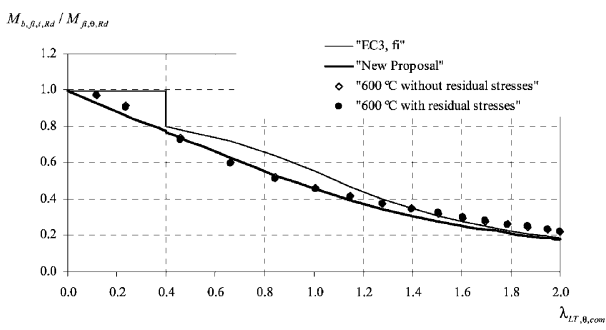

(f)

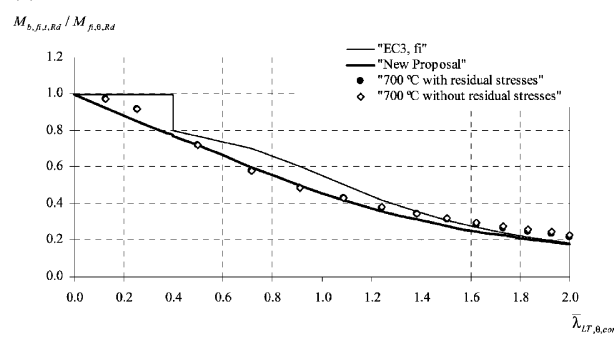

Fig. 9. Beam design curves at elevated temperature.

from Fig. 8 that the influence of the residual stresses is higher for intermediate slenderness of the beams.

Fig. 9 shows the influence of the residual stresses as the temperature increases from 200 up to $700{ }^{\circ} \mathrm{C}$. This figure clearly shows that the influence of the residual stresses decreases with increasing temperature. This is due to the stress-strain relationship at elevated temperature shown in Fig. 5.

\section{Conclusions}

The physical fact that Young's modulus decreases faster than the yield strength when the temperature increases, plus the fact that the stress-strain relationship at elevated temperatures is not the same as at room temperature, produces a modification of the lateral-torsional buckling curve at elevated temperatures. The horizontal plateau valid at $20{ }^{\circ} \mathrm{C}$ up to a non-dimensional slenderness of 0.4 vanishes 
at elevated temperatures. The simple models based on the lateral-torsional buckling curve that is valid at room temperature lead to a safety level that depends on the slenderness of the beam, the results being unsafe for a certain range of the slenderness [5]. To overcome this problem, a new beam design curve has been proposed.

The fact already known by experimental tests at room temperature that the influence of the residual stresses in the lateral-torsional buckling of beams is bigger for intermediate slenderness has been numerically confirmed.

Finally, it was also shown that the buckling resistance of the beams is less sensitive to the residual stresses when the temperature increases. This is probably the result of the smaller difference between yield stress of steel and the level of residual stresses that is characteristic of elevated temperatures. It is also noted that no heat treatment phenomena that should eliminate residual stresses were taken into account in the numerical simulations, an issue certainly worth some attention.

\section{Acknowledgements}

This work was performed in the course of the research project PRAXIS/P/ ECM/14176/1998 sponsored by the Portuguese Foundation for Science and Technology.

\section{References}

[1] Trahair NS. Flexural-torsional buckling of structures. London: E\&FN SPON, Chapman \& Hall; 1993.

[2] Nethercot DA. Limit states design of structural steel work, 3rd ed. SPON Press; 2001.

[3] CEN ENV 1993-1-2. Eurocode 3-design of steel structures-part 1-2: general rules-structural fire design. 1995.

[4] Vila Real PMM, Franssen J-M. Lateral buckling of steel I beams under fire conditions. Comparison between the EUROCODE 3 and the SAFIR code. Internal report no. 99/02. Institute of Civil Engineering, Service Ponts et Charpents of the University of Liege; 1999.

[5] Vila Real PMM, Franssen J-M. Numerical modelling of lateral buckling of steel I beams under fire conditions - comparison with Eurocode 3. J Fire Prot Eng USA 2001;11(2):112-28.

[6] Vila Real PMM, Piloto PAG, Franssen J-M. A new proposal of a simple model for the lateral-torsional buckling of unrestrained steel I-beams in case of fire: experimental and numerical validation. J Construct Steel Res 2003;59:179-99.

[7] Nwosu DI, Kodur VKR, Franssen J-M, Hum JK. User manual for SAFIR. A computer program for analysis of structures at elevated temperature conditions. National Research Council Canada; 1999 [Int. Report 782, p. 69].

[8] Eurocode 3. Design of steel structures - part 1-1. General rules and rules for buildings. Draft ENV 1993-1-1. Brussels (Belgium): Commission of the European Communities; 1992.

[9] Franssen J-M. Modelling of the residual stresses influence in the behaviour of hot-rolled profiles under fire conditions. Construction Métallique 1989;3:35-42 [in French].

[10] Franssen J-M. The unloading of building materials submitted to fire. Fire Safety J 1990;16:213-27.

[11] ECCS - European Convention For Constructional Steelwork. Technical Committee 8-structural stability, Technical Working Group 8.2-system. Ultimate limit state calculation of sway frames with rigid joints, 1st ed. 1984.

[12] Franssen J-M, Schleich J-B, Cajot L-G. A simple model for fire resistance of axially-loaded members according to Eurocode 3. J Construct Steel Res 1995;35:49-69. 